\title{
Diogenes or Havisham syndrome and the mortuary
}

\author{
Roger W. Byard
}

Accepted: 6 May 2013/Published online: 24 May 2013

(C) Springer Science+Business Media New York 2013

Diogenes syndrome was described by Macmillan and Shaw in 1966 [1], and had the name coined by Clark et al. in 1975 [2] to describe a group of 30 elderly socially withdrawn individuals who presented to hospital acutely ill with extreme self-neglect, dirty homes, and rubbish hoarding (syllogomania). These features differentiated the syndrome from individuals who were merely social isolated [3]. Only half had psychiatric conditions, with many having above average intelligence and previously successful professional or business lives [2]. Although the use of the name Diogenes has been criticized (as Diogenes, a fourth century BC Greek philosopher did not live in isolated squalor or hoard rubbish) [4], over the years more cases of the syndrome have been reported in the literature. Subsequent studies have shown associations with a wide range of neurocognitive disorders including dementia, psychosis, frontal lobe damage, intellectual disability, personality disorders, substance abuse, autism, and affective disorders $[5,6]$. Alternative names that have been proposed include disposophobia, or messy house, Havisham, and senile squallor syndromes. Miss Havisham in Dicken's novel "Great Expectations" was, in fact, probably a better example of an individual suffering from this condition $[6,7]$.

A clue to the diagnosis may be the identification of abnormal collecting habits or "collectionism" during life where an individual amasses a large range of items and stores them in a disorganized manner [8]. It has been estimated that problems with hoarding may affect as many

\section{R. W. Byard ( $₫)$}

Discipline of Anatomy and Pathology, The University of Adelaide, Level 3 Medical School North Building, Frome Road, Adelaide 5005, Australia

e-mail: roger.byard@sa.gov.au as 1 in $20-40$ individuals at some time in their lives, and that this behavior is now being facilitated by the ease of online buying [7]. The hoarding of rubbish in a home is not an insignificant problem as it can interfere with activities such as sleeping, showering, cooking, and cleaning [7], all of which contribute to a less-than-healthy life style. It may also foster the proliferation of rodents and insects. Hoarding behavior may involve the compulsive collection of animals which contribute to the overall level of squalor and filth. Post mortem feeding on bodies by animals may create certain forensic problems in a variety of circumstances, not just Diogenes syndrome [9-11].

An ongoing problem with medicolegal cases in many jurisdictions is the lack of detailed death scene descriptions by attending police officers if a case is considered to be not suspicious. For this reason it is likely that the number of cases that are identified as Diogenes syndrome after autopsy is an underestimation. Since reviewing the forensic issues that occur in Diogenes syndrome [11], it has become clear that the syndrome may be involved in a wide range of deaths. Examples include a hypothermic death in a socially isolated elderly woman who fractured her hip following a fall [12], and the case of fatal exsanguination from an undiagnosed rectal carcinoma in a reclusive male that has been reported in this issue of the journal [13].

Does it matter whether a case is identified as Diogenes syndrome or not? The answer to this question is "yes," as the syndrome has a number of characteristic and sometimes bizarre features which can potentially confuse investigators. Individuals who suffer from the syndrome are isolated and shun medical attention. For this reason they may not be found for some time after death with changes of decomposition, such as purging of fluids, raising suspicions of inflicted injury. The lack of recent medical attendance and unusual features at the scene increase the chances of cases 
becoming medicolegal [14]. Decomposition may also introduce numerous other artefacts at autopsy. The characteristic disarray of dwellings may lead to concerns that the house has been ransacked, and that injuries sustained from falling due to illness or alcohol abuse (with failure to seek help) are not accidental [11]. Post mortem animal predation, both from domestic animals such as cats and dogs and from feral animals such as rats and mice, may simulate inflicted injury, or may complicate the autopsy assessment if significant organs are missing. Visual identification may not be possible if animal feeding has removed facial features. Animals may have also tracked purged fluids through the house, further confusing the scene [11].

An awareness of the features of Diogenes syndrome is important in helping with the evaluation of these death scenes, and in explaining a number of features that may be found at autopsy, such as wounds incurred after death from animals and advanced untreated diseases. Evidence of dehydration, malnutrition, and infection should be specifically sought in such cases [15]. The increasing numbers of elderly individuals in Western societies will in all likelihood mean that more cases of Diogenes syndrome will be presenting for forensic examination. However, a prospective evaluation of cases with careful review of the death scene findings will be the only way to accurately determine the incidence of this strange syndrome in forensic practice, and to differentiate it from cases where the main feature has been social isolation.

\section{References}

1. Macmillan D, Shaw P. Senile breakdown in standards in personal and environmental cleanliness. Br Med J. 1966;2:1032-7.
2. Clark AN, Manikar GD, Gray I. Diogenes syndrome. A clinical study of gross neglect in old age. Lancet. 1975;1:366-8.

3. Gurley RJ, Lum N, Sande M, Lo B, Katz MH. Persons found in their homes helpless or dead. N Engl J Med. 1996;334:1710-6.

4. Marcos M, de la Cruz Gómez-Pellín M. A tale of a misnamed eponym: Diogenes syndrome. Int J Geriatr Psychiatry. 2008;23: 990-1.

5. Boyd AM, Alexander J. Diogenes' syndrome and intellectual disability: an uncommon association or under diagnosed? Aust NZ J Psychiatry. 2010;44:488-9.

6. Cipriani G, Lucetti C, Vedovello M, Nuti A. Diogenes syndrome in patients suffering form dementia. Dial Clin Neurosci. 2012;14:455-60.

7. Freckleton I. Hoarding disorder and the law. J Leg Med. 2012; 20:225-49.

8. Montero-Odasso M, Schapira M, Duque G, et al. Is collectionism a diagnostic clue for Diogenes syndrome. Int J Geriatr Psychiatry. 2005;20:709-11.

9. Buschmann C, Solinaro B, Püschel K, et al. Post-mortem decapitation by domestic dogs: three case reports and review of the literature. Forensic Sci Med Pathol. 2011;7:344-9.

10. Byard RW, James RA, Gilbert JD. Diagnostic problems associated with cadaveric trauma from animal activity. Am J Forensic Med Pathol. 2002;23:238-44.

11. Byard RW, Tsokos M. Forensic issues in cases of Diogenes syndrome. Am J Forensic Med Pathol. 2007;28:177-81.

12. Bright F, Winskog C, Gilbert JD, Byard RW. Additional risk factors for lethal hypothermia. J Forensic Leg Med. (in press).

13. Freeman A, Byard RW. Fatal hemorrhage from an undiagnosed rectal carcinoma in a case of Diogenes syndrome. Forensic Sci Med Pathol. doi:10.1007/s12024-013-9444-4.

14. De-Giorgio F, Grassi VM, Chillemi E, Martinotti G. Dead under the bed: a case of Diogenes syndrome? Int J Geriatr Psychiatry. 2013;28:547-9.

15. Bonci G, Varghese E, Mahgoub N. A case of Diogenes syndrome: clinical and ethical challenges. J Am Geriatr Soc. 2012;9: 1780-1. 